\title{
Traditional Leather Processing, Production and Marketing in Amhara Regional State of Ethiopia
}

\author{
Bisrat Gebremichael \\ Livestock Industry and MD Advisor/LMD, Addis Ababa, Ethiopia \\ Email: bisregbu@gmail.com
}

How to cite this paper: Gebremichael, B. (2016) Traditional Leather Processing, Production and Marketing in Amhara Regional State of Ethiopia. Open Access Library Journal, 3: e2751.

http://dx.doi.org/10.4236/oalib.1102751

Received: December 1, 2016

Accepted: December 26, 2016

Published: December 29, 2016

Copyright $\odot 2016$ by author and Open Access Library Inc.

This work is licensed under the Creative Commons Attribution International

License (CC BY 4.0).

http://creativecommons.org/licenses/by/4.0/

\begin{abstract}
A study that explores the livelihoods of the traditional tanners was conducted from November 2013 to April 2014 with the objective of assessing the prevailing traditional leather production and processing knowledge, business environment in Amhara regional state of Ethiopia. In-depth interviews were carried out through direct observation, focal group discussion using a semi-structured questionnaire by interviewing 30 households located in 3 zones of Amhara region and those who work on traditional tanning. The result indicated traditional leather products are important household materials and income generating business especially for the rural community. To produce traditional leather products, they follow different steps and procedures and to facilitate this process in between, they apply different materials and indigenous vegetables. The involvement of traditional tanners in the market is significant that the volume of raw cattle hide they absorb for producing traditional leather goods is more than 600,000 per annum. All the local tanners who work through the process were made up of young and middle-aged men. By tradition, local tanners in Ethiopia belong to a low-caster and are looked down upon by other parts of the community. Artisanal group has suffered from prejudice and relative isolation in society. Considering the high amount of produced leather waste which contains toxic and pollutes plant residues, there should be a great interest to develop a water collection center in the nearby surrounding so as to protect pollution of water bodies which are reserved both for humans and animals.
\end{abstract}

\section{Subject Areas}

Agricultural Science

\section{Keywords}

Traditional Tanners, Traditional Leather Products, Hides and Skins 


\section{Introduction}

According to [1], Ethiopia is a home for 56.7 cattle, 29.3 sheep and 29.1 goats. This indicates the country possesses the largest livestock population in the world. Traditionally livestock is an important sub-sector within Ethiopian Economy in terms of its contribution both to agricultural value-added production and to the national economy. Livestock contributes to the production of meat, milk, eggs, blood, industrial raw materials, wool, hair, hides and skin. Leather from animal skin has been chemically modified to produce a strong, flexible material that resists decay.

All hides and skins that enter the market for transformation into leather originate from slaughter animals that provide for meat, and hence their hide or skin is a by-product of the meat industry. According to [2] [3], annual off-take rate has reached 9.77, 34.61, and 26.11 per cents for bovine animals, sheep and goats respectively and the annual output is estimated at about 5.2 million, 8.8 million, and 6.2 million pieces of bovine hides, sheep and goat skins. So, this indicated Ethiopia is endowed with the resource base required for the commercial production of leather and leather products. Contrarily to other commodities, as far as meat consumption is concerned, hides and skins are produced everywhere, in each village and town, in each and every country, all over the world, without exclusion. Each continent and all seas and oceans produce hides and skins. Where there are people, independent from race, religion or political association, there is a production of hides and skins. There isn't a type of animal in the world that doesn't or hasn't provided the basic material for the production of leather. Currently, 30 tanneries and 18 enterprises manufacturing leather products operate in the country producing products ranging from various forms of leather articles such as shoe uppers, leather garments, stitched upholstery, school bags, handbags, industrial gloves and finished leather.

Parallel to modern tanning, Ethiopia is also one of the African countries with the presence of huge number of traditional tanners. It is estimated that there are about more than 6722 household traditional tanners in the country, mainly scattered in the northern part of Amhara, Tigray and Oromia regions of the country. In Amhara region alone, 5292 traditional tanners are found. Nationally they have a capacity to utilize more than 700,000 hides per annum. They purchase huge amount of hides due to their ability to pay better price than tanneries and their availability in the nearby compound. In many civilizations around the world, animal hides and skins were processed and used for various purposes since time immemorial. Even if the involvement of local tanners in collecting the hides in market is significant, the number and capacity of stakeholders in this group have not been exhaustively studied. Detail analysis on the utilization, processing, marketing and future prospect was not exhaustively investigated. Hence this study mainly focused on undertaking to examine the process, the marketing and methods applied in the traditional leather production.

\section{Methodology}

\section{Description of Study Area}

Amhara regional State is one of the nine administrative regions of Ethiopia andthe re- 
gion comprise 10 zones, 1 special zone and 128 district/werdas and covers an area of $170,532 \mathrm{Km}^{2}$.

The region is the land of diverse topography and the altitude varies from 500 4620 meter above sea level at Ras Dejene and much of the region is high land (>1500 meter above sea level) and the human population is about 16 million with an annual growth rate 3\%. Population Density of the region is about 94 person $/ \mathrm{Km}^{2}$ and the rural population accounts for $89 \%$ of the total population of the region. Agriculture is the main stay of the economy engaging $89 \%$ of the rural population and smallholder mixed farming dominates (80\%), and livestock is an integral part of the farming system.

\section{Map of Study Area}

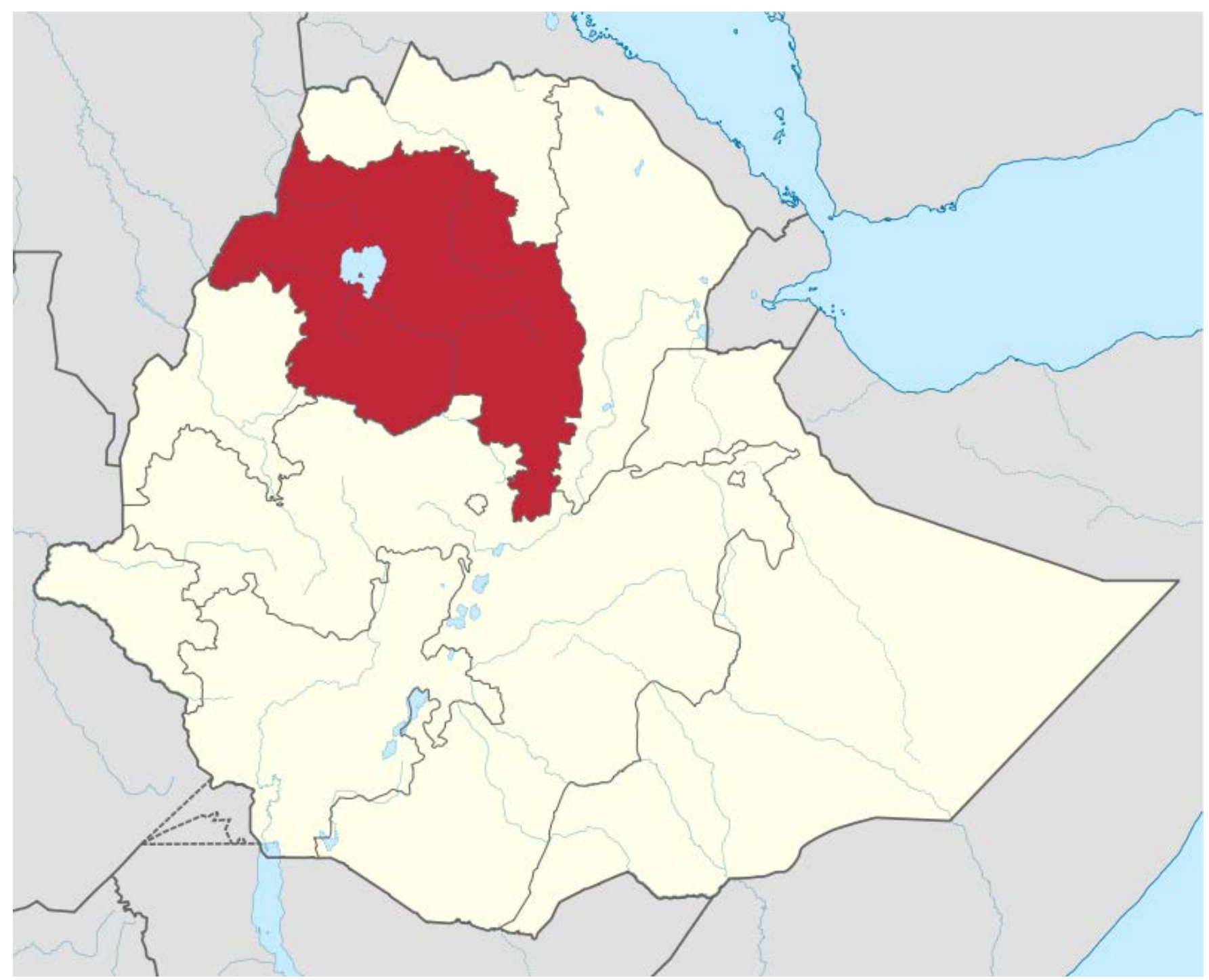




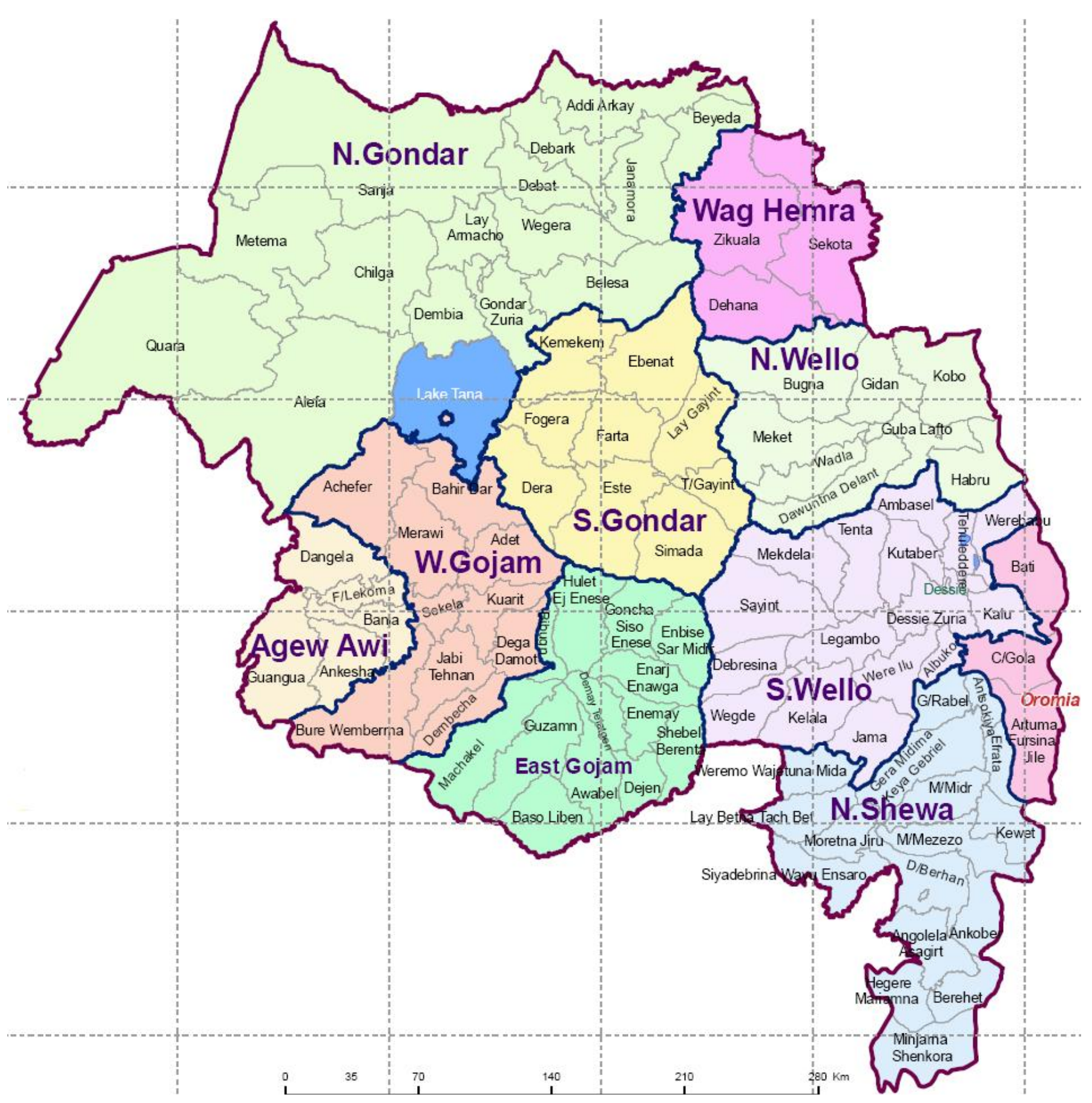

\section{Data Collection}

A researcher accompanied with data collector, a detailed and organized semi structured questionnaire was designed to generate base line information related to traditional leather processing with particular emphasis on major leather production and marketing.

The questionnaire was framed in such a way that tanners could give information that are recent and easy to recall and it was filled directly by interviewing 30 randomly se- 
lected elder male local tanners who perform traditional leather processing in addition to farming from different villages of the 3 peasant associations for three consecutive weeks. Informal group discussion with development agent had also been held to generate relevant information about traditional leather production problems in the study area.

The interview questions include: list out the major steps in traditional leather processing, how many days does it take to produce a single product based on the item product, purpose of using cattle hide, problems faced during purchasing of cattle hide, social status of tanners, type of tanning agents (Figure 1).

\section{Data Analysis}

Qualitative data derived from direct observations from tanners and key informants were examined and presented in form of discussions and descriptive data's were analyzed using descriptive method of analysis.

\section{Results}

\subsection{The Nature of the Traditional Tanning Work}

The involvement of traditional tanners for competing and purchasing hides in the market is significant that the volume of raw hide they absorb is more than 600,000 per annum.

All the indigenous family members of tanners who work through the leather process were males. They were made up of young and middle-aged men. The old men in the profession were no more working effectively as they used to. All the indigenous tanners interviewed said that their profession used to be very good some years back. Most of the indigenous tanners had been in the profession for a very long time inherited from their ancestors. In some areas of the community because of complains coming from the expansion of urban communities, they are forced to drop their work except those leather products which doesn't need un-hairing.

\subsection{Social Status of Local Tanners}

Traditional handicrafts in Ethiopia are a vocation and a way of life. Despite increasing

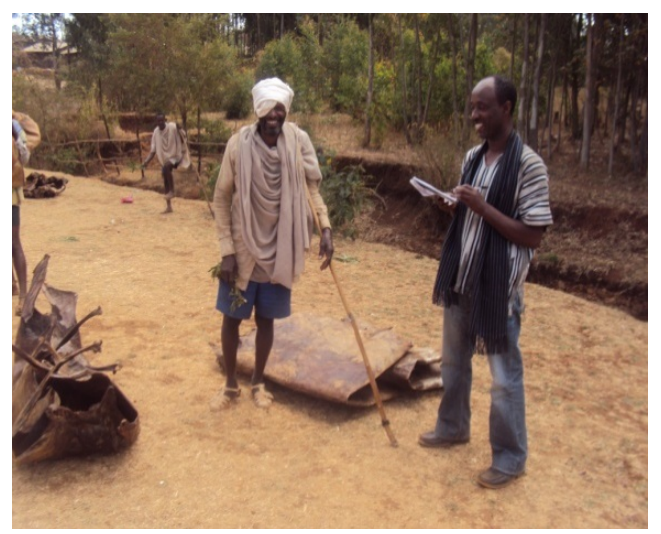

Figure 1. Semi-structured interview with local tanners. 
threats from much cheaper, more convenient and readily available substitutes, Ethiopia's age-old traditional handicrafts are not yet banished, but still serve as allures of gift shops for tourists and are decisively instrumental in the lives and occupations of many rural communities.

Traditional tanning is usually the professions that give a different status to their practitioners. It is a labor intensive undertaking as the majority of the processing and manufacturing of cottage industry.

Many of the families and workers live around the local tanneries and their skills are passed down from generation to generation through the male lineage.

By tradition, local tanners in the study area belong to a low-cast and are looked down upon. This artisanal group has suffered from prejudice and relative isolation in society and they are only accepted to make marriage among themselves. Others don't make parental relationship with them.

\subsection{Processing Aspects and Impacts to the Environment}

Traditional leather production is one of the polluting cottage industry around the communities This happened because of generations of huge amount of solid and liquid wastes such as wastes of fleshing, buffing dust, skin trimmings, hair drops and poison plant residues left after processing, emitting of obnoxious smell due to degradation of proteinous material of hide and generation of gases such as $\mathrm{NH}_{3}, \mathrm{H}_{2} \mathrm{~S}$ and $\mathrm{CO}_{2}$. Accumulation of these wastes leads to sludge problem. Even if treatment of solid wastes were not cost effective, they were not in a position to create a new way of processing. Traditional leather processing in the study area are facing lot of solid waste problems and many local tanneries drop their works due to external forces of the nearby cities and urban dweller expansion for not meeting environmentally friendly production of leather (Figure 2).

\subsection{Marketing of Hides}

Compounding the small size problem for modern tanneries is that traditional tanneries market and manufacture all kind of products widely used by the rural household that do not require large, well-preserved, or unblemished hides. Therefore the traditional tannery, the demand for whose products remains strong, can purchase a large volume of all types and sizes of hides before they ever circulate in the formal hide and skin val-

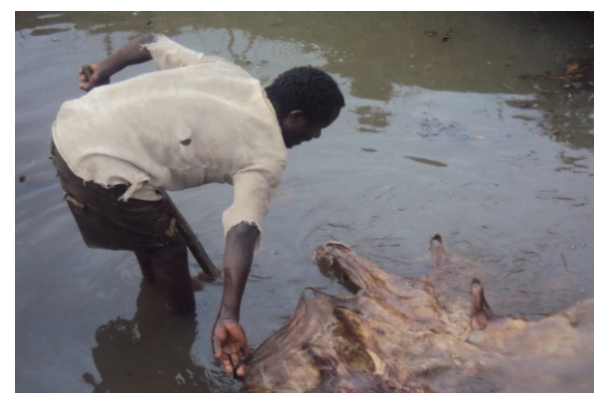

Figure 2. Hide soaking I the nearby river. 
ue chain for purchase by modern tanneries. In the study areas, traditional tanneries operate as the most convenient buyer for small producers, since producers can sell to the traditional tannery whatever type and grade of hide they have as they are located in the nearby community.

The selling and buying of hides in the study area has its own demarcated area where mostly carried out on market days that are held mostly once in a week on Saturday. About $95 \%$ of the major producers of hides mainly sell dried or green hide directly no middlemen are involved. The buying and selling practice is traditional in which buyers and sellers directly bargain based on the past market price, physical size of the hide and the presence or absence of visible defects on the raw stock. In these market areas $95 \%$ are all poorly dried hides that stayed at home more than $4-10$ days after slaughter (Figure 3).

\subsection{Hide Consumption Rate}

According to field survey report [4], in Amhara region, there were more than 5299 local tanners that consumed $85 \%$ of the region's hides, for processing to different traditional leather products, on average each local tanners utilize 9 hides per month amounting 626,569 hides per annum (Table 1). It is therefore important to investigate the pros and

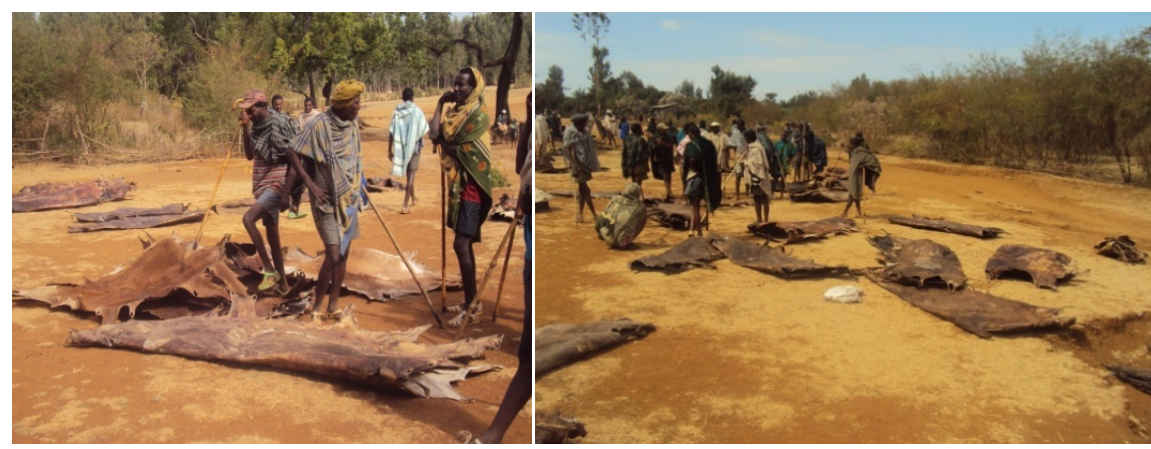

Figure 3. Traditional market area for hides and leather products.

Table 1. Number of local tanners and their distribution in the region.

\begin{tabular}{ccccccc}
\hline Administrative zone & $\begin{array}{c}\text { Number } \\
\text { of tanners }\end{array}$ & Share in \% & $\begin{array}{c}\text { Annual } \\
\text { consumption }\end{array}$ & $\begin{array}{c}\text { Farming and } \\
\text { tanning }\end{array}$ & Tanning & Remark \\
\hline South Gondar & 929 & 17.5 & 201,593 & 803 & 126 \\
North Gondar & 630 & 11.9 & 151,200 & 580 & 50 \\
West Gojam & 1170 & 22.1 & 94,160 & 830 & 347 \\
East Gojam & 546 & 10.3 & 50,176 & 440 & 106 \\
North Wello & 760 & 14.3 & 47,040 & 649 & 111 \\
North Shewa & 732 & 13.8 & 24,122 & 726 & 6 \\
South Wello & 497 & 9.3 & 58,116 & 202 & 295 \\
Oromia & 28 & 0.5 & 162 & 27 & Na \\
Total & 5292 & 100 & 626,569 & $4257(80 \%)$ & $1041(20 \%)$ \\
\hline
\end{tabular}

Source: BoA, 2001. 
cons of the local tanning industry when designing any development strategy or program for hide marketing.

According to the information derived from the region, south Gondar and west Gojam are the leading zones in having highest number of local tanners in the study area of the region.

The study showed that traditional leather tanning in the study area has been practiced along a family-based rural social cottage structure for decades, using traditional techniques and materials to produce traditional leathers.

All the traditional tanners interviewed in the communities said this business were males aged between 17 to 65 years. The respondents pointed out that on average they have been processing leather for between 5 to 40 years.

The local tanners explained that the skill was acquired from their grand fathers, fathers, brothers, relatives or other male tanners in their communities. They all concurred that they only tanned hides from cattle (bulls, heifers, calves).

The hides which were usually processed from the dried state except occasionally bought fresh products were either flayed by the local tanners themselves or purchased from the nearby village or neighboring market which was demarcated and sited separately from the live animal trading centers (Table 2).

The traditional processing of hides into leather is a complex procedure that requires a precise combination of many chemical and or mechanical operations.

\subsection{Preparatory Stage}

\section{Stage 1-Raw hide Collection}

The start of the traditional tanning process begins with the collection and sorting of the raw hides. The types of hide usually used are cow and bull/oxen hides.

Traditional tanners usually bought hides from the nearby market (Figure 3); however, they also buy from big suppliers especially when prices fall in the market with subsequent fall in demand for raw products. In such a situation, they manage to pay better prices as compared to prices paid by tanning industries or raw hide skin suppliers.

Focus of the traditional leather producing cottage industry is the transformation of untreated hides that are brittle under dry conditions and may rot under wet conditions

Table 2. Materials used.

\begin{tabular}{ccc}
\hline Items/materials & Use & Remark \\
\hline Hides & For processing into unappreciable leather product \\
Scraping Knife & Fleshing \\
Anderground hole earthenware pot & Soaking, tanning \\
Sticks/chikal & For removing hair \\
Seewing needle/“wosfe” & For stretching the soften hide \\
\hline
\end{tabular}

Source: Author's Fieldwork. 
into durable, imperishable leather by processes which incorporate tanning agents into the hides.

After the local tanners bought dried hides, the processes in converting hides into durable product, commonly there are basic practical steps followed in the area. Leather production involves various preparatory stages, tanning, and crusting. These stages have been classified under three broad arranges as follows; the preparatory stage, tanning stage and the crusting stage. The first task for the local tanners is to collect the raw hide and this is usually a cow hide dried by sun or in very few occasions fresh hide collected from primary producers and small traders in their vicinities.

Those in which the hide is prepared for tanning it includes soaking, washing, flesh removal, hair removal, scudding and deliming.

\subsubsection{Soaking/Washing}

The dried hides collected from market are subjected to become soft by soaking the hides in the river basin (Figure 4). Soaking Solid waste in the local tanners the main wastes are solid by products and liquid wastes. These include hide dusting, raw hide trimmings, and hair from liming and then rinsing is the first step in traditional leather making. According to the interview, the first step when traditionally making hides into leather is to thoroughly clean them. Soaking will help soften the hides, making the next steps easier to perform and important to remove dirt, debris, blood and excess animal fat from the hides. This has been done by simply soaking the hides in water for about 3 days in the nearby river; tanners with bare foot will immerse early in the morning and bring back to home during evening for just protecting from theft and carnivorous animals. The next day they will take to the river, the same steps will be followed for 3 consecutive days depending the nature and thickness of the hide. Washing will help soften the hides, making the next steps easier to perform. The purpose of this operation, as the local tanners explained, was to increase the amount of water in the hide close to that of the living hide, remove foreign bodies, hair and loosen the hide structure. The waste river water is discharged into a river where both animals and even on the upper part used for human drinking. No water treatment mechanisms are set.

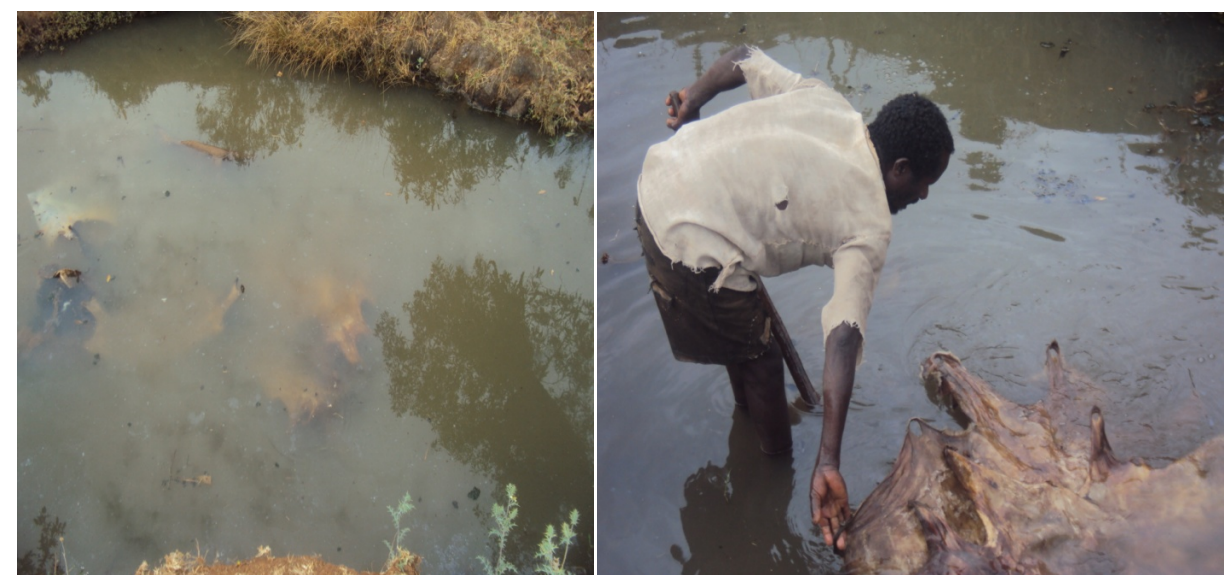

Figure 4. Soaking of hides in the nearby river. 


\subsubsection{Fleshing}

After the hide become relatively soften, they bring back to their backyard around homestead and dry on the sun by stretching on the ground using woods for stretching (Figure 5). The flesh side of the stretched hides will be on the above sun side for fleshing.

The process of removing hair from hides required a knife and small axes.

Fleshing is just to cut away unwanted fat and flesh. In this process, hairs are removed through knife and axes.

Removing any fats and other unwanted flesh debris using scraping tools/sharp axes in between while drying on the sun, they sprinkle pieces of water. According to the interview, the aim of this process was to loosen the flesh and unwanted fat still adhering to the materials. Excess flesh, fat and muscle must now be removed from the hides. This was done with a fleshing axe. The scraping axes were then used vigorously to remove the fats and meat leaf from the grain side of the hide.

To make soften more, the fleshed stretched hides were taken back to river to stay one extra day.

\subsubsection{Un-Hairing}

The soaked hides are transported to tan pit or vats immersed in a mixture of cow urine, grinded vegetable fruits and water (Figure 6). These mixtures loosen excess fat, flesh
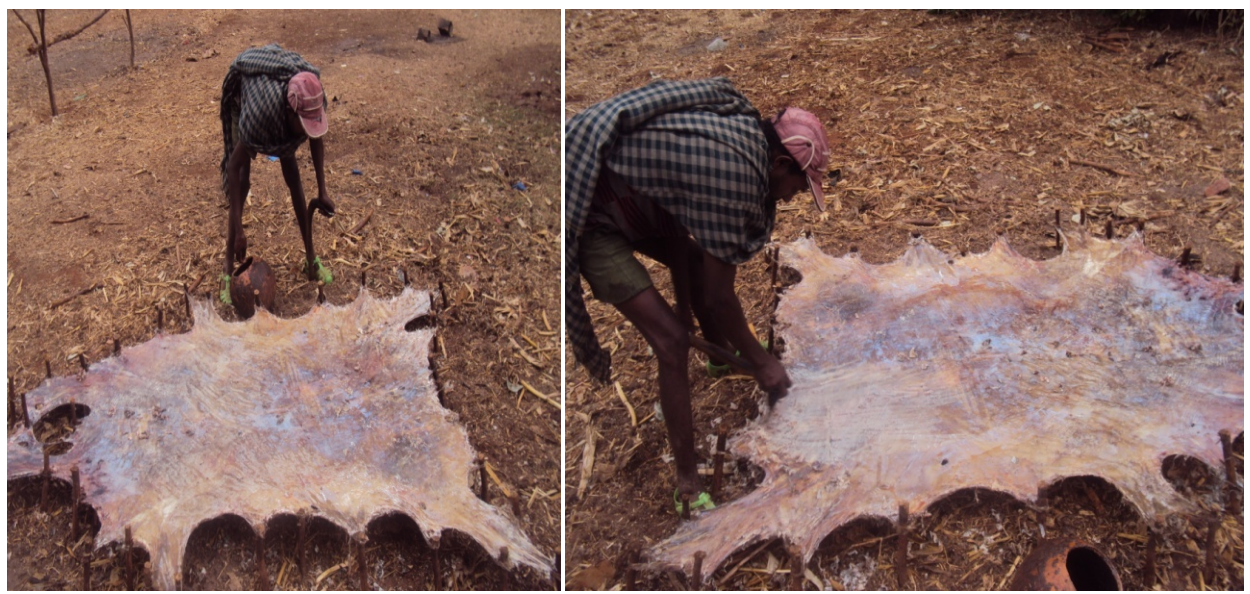

Figure 5. Removal of fat and excess flesh.

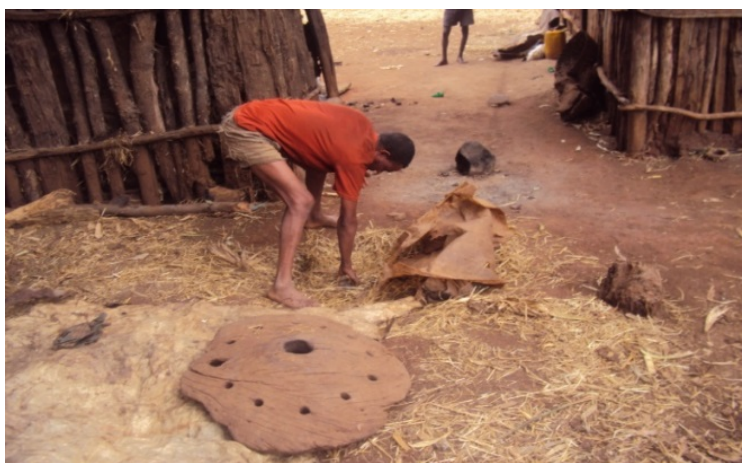

Figure 6. Hides soaked in mixed vegetable and cow urine. 
and make easy to make to remove the hair, epidermis and to prepare the hides for removal of loose flesh and fat during fleshing process.

The hides were soaked with a solution containing part of the plant containing tan from vegetables which are usually ground into smaller pieces is immersed in a solution containing 10 - 20 liters of cattle urine or in cases where vegetable is not available, 10 pieces of another plant fruit is allowed to leach out into 5 litres of cattle urine ,buried in a large pit dug out from the ground, which you would have to stir manually with a large, wooden paddle and remain in the solution in underground for about 24 hours or up to 3 days based on the nature of the processed hide.

It was observed that when left for longer periods in the bath, creating holes in the hides and may decay easily. The respondents explicated that the process aids in loosening the hair follicles, which enables the easy removal of the hair from the hides. The liming process they add, also removed fat from the hide for tanning. After these steps again it were allowed to be stretched back on the ground exposing to air and direct sun light.

\subsubsection{Tanning Stage}

The final stage in the traditional leather making process was laid out and stretched to dry on the ground were allowed to be mixed with milled oil seeds for making the leather smooth, colorful and shiny.

The raw collagen fibers of the hides must be converted into a stable product which is no longer susceptible to rotting. This is done by adding vegetable tanning. The vegetable material used for tanning in the final stage is local named as "Kachima". According to the tanners, this oily vegetable is important in making shiny, smooth and colorful for the processed leather good. Probably these tanning agents significantly improve the hide's dimensional stability, abrasion resistance, resistance to chemicals and to heat, the ability to flex innumerable times without breaking.

\subsubsection{Crusting Stage}

\section{Drying, Softening and Oiling}

The immediate post-tanning activities are drying, softening and oiling. The tanned leathers were first dried on a drying line and allowed to dry partially before commencing the softening process. The artisans regularly turned and reposition the leathers. The technique normally used by the tanners to soften and stretch their leathers was to wrap part of the leather around a stick and dragging it between a flat-ground after satisfactorily softening and stretching the leathers, they were then oiled using vegetable oil (Rhusnataliensis). 4 kilos of vegetable oil (Rhusnataliensis) was oiled uniformly on the grain surface of the product. After oiling, the leathers were sorted out and bended equally to make it easily transport from place to place.

\subsection{Traditional Leather Products}

Handicrafts are not commodities merely produced by hand, but something created by local tanners whose energy and spiritual outlook were translated into products with the 
aid of raw materials, tools and his skills.

Traditional tanners' processes hides and change to leather of various forms among the most common ones include bags, wallets, belts, musical instruments, traditional kitchen goods, baby carrier (called a mahazeya or ankelba) traditionally treated hide decorated with cowries shells, sleeping mat, bags for grain transportation, hat, bracelets, leather made chair, package for praying book pocket and many more tourist attraction traditional leather products. In the study area, there are lots of leather products that are locally manufactured using the products originally came from local tanners. As compared to other products, these leather products are durable and stay longer period of time without any damage on the collagen part of the leather. So it makes the product highly popular in market and tourist attraction goods.

\subsubsection{Sleeping Mat}

As seen in Figure 7, Local name "Jendi" or in others named as "korbet" rural sleeping mat, these sleeping leather products are usually purchased by rural family members or by farmers used as a sleeping bed stretched usually on the floor at home. Likely it brought warm environment during cold weather.

\subsubsection{Book Binding}

Leather used in book binding has many of the same preservation needs: protection from high temperatures, high relative humidity, low relative humidity, fluctuations in relative humidity, light exposure, dust buildup, pollution, mold, and bug infestation (Figure 8).

\subsubsection{Dyeing of Leather}

Black and cinnamon brown were the only two colours dyed in the three communities during the study period.

Even though the tanners claimed they could dye other colours such as yellow, blue, and green on request, none of the above mentioned colours were produced during the research period. The cinnamon dye was prepared from millet husk (eleusinecoracana), whiles the black was constituted from a compound containing fermented liquids and

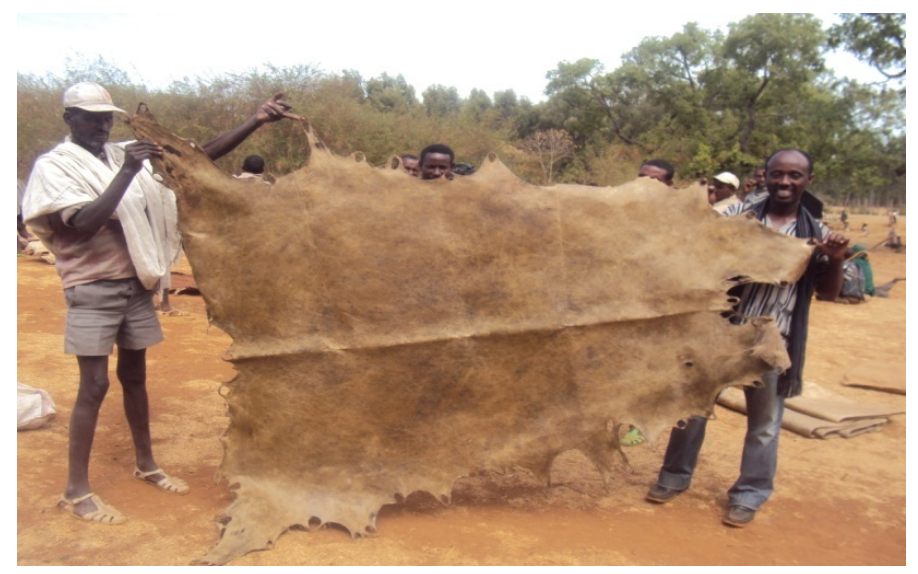

Figure 7. Sleeping leather mat/Jendi. 


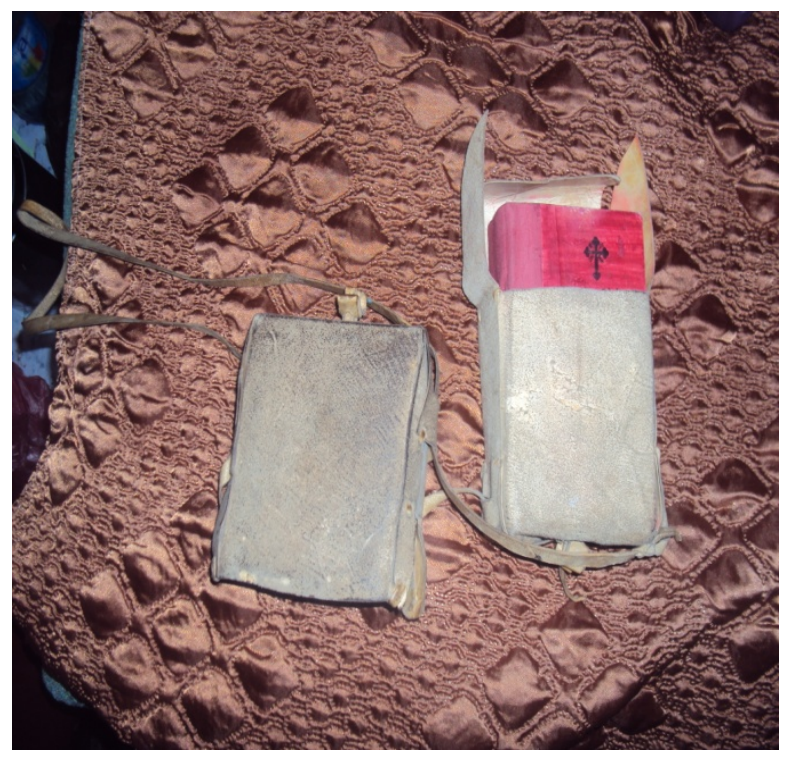

Figure 8. A set of leather bound spiritual books.

rusted iron materials.

\section{Discussions}

The findings of the study show quite clearly that the tanning processes used by the leather tanners in the study area even though scientifically proven, was plagued with some challenges. The researcher observed that proper rinsing was scarcely carried out in the three tanning communities during the tanning processes. Largely, it was discovered that the offensive odor associated with the tanned and dyed leathers were imparted at stages during the tanning processes specially prior to fleshing.

In the preparation of the compound, which aids in the fleshing process, it was realized that the residuary solution which was used in soaking and washing the dry leathers as part of the soaking and washing process, was again fetched and mixed with fowl droppings, pounded papaw and pumpkin leaves for use as fleshing bath. A major source of the bad odor therefore may be attributed to the re-using of this waste water. Even though the fowl droppings may also be seen as imparting some obnoxious characteristics, they are rather known to contain nitrogen, oxygen and hydrogen 2, which are essential in fighting against the strong smell associated with the tanning process as well as speeding up the cleansing process (Zaruwa and Kwaghe, 2008).

\section{Prevention and control measures for solid waste include the following}

Generally, the study has observed that proper rinsing was not carried out by the tanners during the tanning processes. As variously explained by the tanners, the limited amount of water available to them, makes it quite difficult for them to rinse the hides diligently during the tanning processes. It was observed that water for tanning was fetched from a river which is $1-2 \mathrm{~km}$ far from the study area however; a hand dug well was the main source community.

\section{Constraints in production and marketing of hides}

Producers include production of low quality of hides due to poor methods of curing 
such as sun dying, poor flaying due to lack of flaying skills and lack of proper flaying tools. Poor transportation means to the markets. The prices of hides keep on fluctuating.

\section{Mechanical damage}

When hides are being prepared for air-drying by the framing method, it is customary to remove excess flesh left on the hide by de-fleshing. This is normally done using a concave knife and or axe on the ground where the hide is spread with the flesh side facing up. Most times the tanners taking off the flesh do not take care as they try to make the hide too clean by getting maximum amount of flesh out. During this process hides suffer flay cuts and gouges are made.

\section{Conclusions and Recommendation}

\subsection{Conclusions}

The study conclusively showed that traditional leather tanning in the study area is a male dominated job. This is because of the tidiness of the work which could be difficult for females.

This process was passed down the male family line. The raw materials and tools for tanning were largely sourced from the community. Solid wastes generated in the traditional leather processing pose pollution problem in terms of sludge.

The research revealed that even though the traditional tanning methods used to process tanned leather from the above mentioned communities in the city and peasant association or municipality followed sound scientific tanning procedures, tanned leathers from these suburbs, are noted for exhibiting offensive odors because the tanners do not adequately rinse the skins in the right manner during the tanning stages, due to the limited amount of water available to them.

Environmental regulations for the traditional tanning are not equally stringent as the international regulations, and the pollution load coming from the traditional tanneries is still heavy, and it is a problem both for the people living nearby, and for the river water. All local tanneries still fail to operate properly as of the prescribed equipment to do primary treatment. Many of the local tanners believe their activity is not harmful to the environment, or they do not see the environment as something that needs to be protected or treated properly. It is important to acknowledge that the opportunities for technological upgrading could trigger a better use of resources and hence reduce the production of waste. Implementing technology or even cleaning mechanisms is a problem particularly for the many tanneries that are in a poor financial position.

\subsection{Recommendations}

\section{1) Recommendation One}

During processing, traditional leather industry as a whole is responsible for generating huge amounts of waste as a by-product of its production. The traditional leather sector is well known for its effluent problems. The polluting nature of tanning activity is evident from the notorious odour that characterizes traditional tannery zones. 
Considering the high amount of produced leather waste which contains toxic and polluting, plant residues there should be a great interest to develop and investigate new methods and alternatives for the commercial tannery to realize environmental protection and sustainable development (Figure 9).

Because the nature of the leather processing has been categorized as one of the highly polluting tasks and there should be concerns that leather-making activity can have adverse impact on the environment and the nearby community. Among waste products generated during the process include solid wastes (fleshing, skin trimming products like hair) and liquid wastes (polluted river).

Because of absence of immediate solid waste burying trend, solid wastes of the trimmed products such as legs, belly, neck, and tail parts are found here and there, bare on the ground remaining around the homestead. Local tanners are not using gloves during solution making, but they just use their bare hand to make the solution. Moreover, during soaking the hide, they put their bare foot in the polluted water base. The polluted rivers simultaneously are also used for watering plants and used for drinking animals in the nearby community. All these occasions made traditional tannery generated huge amount of solid and polluted liquid wastes leather processed products and susceptible to be easily infected with microorganism and become ill. Therefore, in each community due attention for constructing a big underground pit hole for burying solid wastes, should be given. For liquid wastes, either a fenced nearby water points/birkas' reserved only for soaking should be established or provide them big watering jar or to soften and remove excess dirt and blood stain a pit should be constructed.

In the traditional leather processing communities even if dogs are considered as one of the biological solid waste cleaners, in human health aspect these dogs have a chance to transmit some micro organisms and or zoonetic diseases to the family members of the owners. During our surveillance, we also observed that chicken are also participating in consuming trimmed fat and waste products which would affect their health and

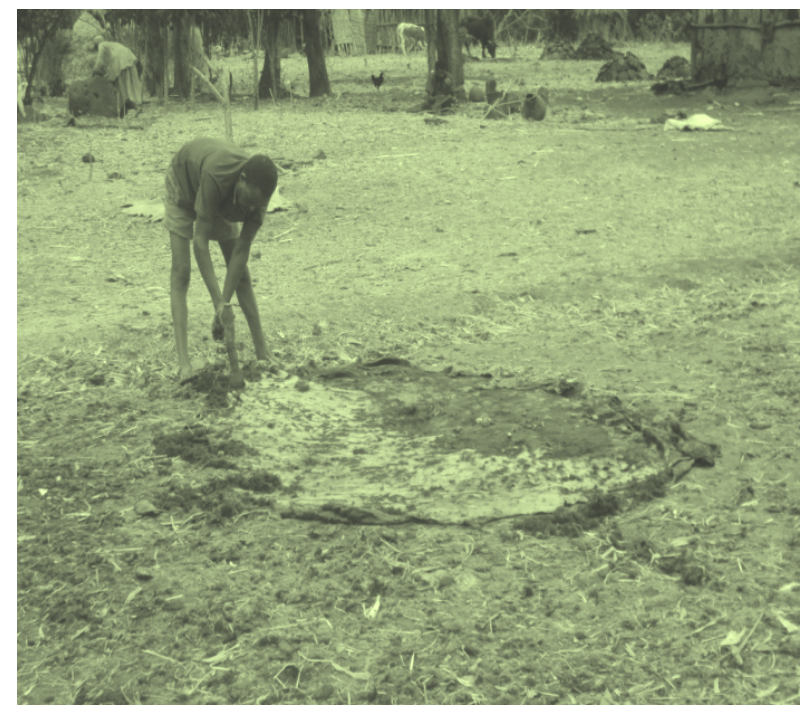

Figure 9. Solid wastes generated during de-hairing. 
probability to transmit to all chickens in the community. According to the respondents, the agricultural experts and health workers don't visit these areas even to make them aware of the danger and such occasions as well as to use other moderate materials processing instruments, therefore we would like to comment the concerned bodies should visit the events and set appropriate strategies to settle the situation.

Health and educative programmes, seminars and workshops should be organized frequently to educate the tanners concerning the quality of hides for leather.

If there are loan grants from the government and non-governmental organizations (NGO”s), it can help aid the tanners and indigenous leather traders to patronize effectively in the locally tanned leathers.

Therefore, domestic animals shouldn't be allowed to consume solid wastes as they have a great chance to transmit easily to the surrounding community.

Because of presence of various solid and liquid wastes released during the process, Whenever you came to these local tanners community, due to degradation of proteinous material of hides and generation of gases (such as $\mathrm{NH}_{3}, \mathrm{H}_{2} \mathrm{~S}$ and $\mathrm{CO}_{2}$ ), there are high emit obnoxious bad smell in the area.

The hides are trimmed (especially at legs, belly, neck, and tail parts) in order to give them a smooth shape but there is no trend or absence of available animal farms, the trimmings are not usually sold. Either wasted or became pet feed for dogs.

Traditional tanning is a family business and life style which they learnt from their ancestors, therefore, currently it is improbable to stop working these jobs rather better to set a strategy.

Considering the enormous revenue that could accrued from the hide export and leather industry, there need to be great consideration to give them orientation how these products support the export revenue to the country, so continue the traditional leather products, we recommend that they have to establish a small scale cooperative organization so as to address them in group. They can also use rejected hides from tanneries as well as from suppliers this will be made in reality if we can establish a linkage mechanism with suppliers and nearby tanners. By doing these things, we can make hand in hand and increase amount and quality of hides coming to tanneries.

In general, there is a need to take a second look at the tanning businesses in these communities. A systematic development plan needs to be drawn to give the craft industry some qualitative up-grading to boost the economic fortunes of the region and nation as a whole.

The tanners must be trained to acquire innovative and modern tanning leather crafting skills to improve on their tanning skills as well as tanning effluent management. Since water played a crucial role in the process, adequate reserved water needs to be provided for the tanners in all the tanning communities to aid in the efficient processing of high quality vegetable tanned leathers.

The indigenous tanners should work together and adopt standardized criteria for thorough assessment of the quality of skins and hides for indigenous leather production. 


\section{2) Recommendation Two}

Traditionally made bags, wallets, attaché cases, belts, bracelets, just to mention a few, are sparsely distributed and are sources of tourist attraction traditional leather good products. These innovative and aesthetically appealing leather articles are not very well patronized locally or exported much, this is because little have been made to organize them and approach them collectively. But if strategically verified, it could increase the source of foreign currency.

\section{References}

[1] Ethiopian Central Statistics Authority Report 2014/15.

[2] Data Collected from All Regions and City Administrations in 2013.

[3] Bisrat, G. (2013) Defect Assessment of Ethiopian Raw Hide and Skin: The Case of Tanneries in Addis Ababa and Modjo. Ethiopian Journal of Global Veterinaria, 11, 395-398.

[4] LMA, 1999/2000, Field Survey Reports of Regional States.

Submit or recommend next manuscript to OALib Journal and we will provide best service for you:

- Publication frequency: Monthly

- 9 subject areas of science, technology and medicine

- Fair and rigorous peer-review system

- Fast publication process

- Article promotion in various social networking sites (LinkedIn, Facebook, Twitter, etc.)

- Maximum dissemination of your research work

Submit Your Paper Online: Click Here to Submit

Or Contact service@oalib.com 